\section{Neighborhood Deprivation and Self-Rated Health in Lagos State, Nigeria}

\section{Dr. Rasheed Kola Ojikutu ${ }^{1}$}

\begin{abstract}
This study examines the effect of neighborhood deprivation on the perception of the individuals about their own health in Lagos State, Nigeria. Respondents were required to rate their own health as "excellent, very good, good, fair, poor and very poor". The questionnaire contained questions on various aspect of the respondents neighborhood and their perception about them. It was found that most neighborhoods in Lagos State are deprived of basic essentials of life such as electricity, water, good roads and security. Over $43 \%$ of the respondents claimed to have visited a hospital two or more times and $43.7 \%$ had lost at least two neighbors in the past one year. Over half (57.8\%) of the respondents rated their own health as good, 36.6\% ranked their own health as fair while only $5.6 \%$ claimed to have poor health. A fitted regression model $\left(r^{2}=0.644\right)$ showed that variables such as number of dependants, income, occupation, type of residential accommodation, ownership of house, number of rooms occupied, mode and convenience of transportation, accessibility to water, electricity and good roads and security jointly determine the perception of an individual about his own health status.
\end{abstract}

1 Dr. Rasheed Kola Ojikutu has been teaching at the Department of Actuarial Science and Insurance, Faculty of Business Administration, University of Lagos, Akoka.
Key Words: Neighborhood, Deprivation, Self Rated Health, Security, Residence

\section{Background}

Despite several years of investigation, researchers have been unable to arrive at a common position on whether living in a deprived neighborhood increases the risk of poor health. While researchers such as Stafford et al. (2003) believe that relationship between neighborhood status and health cannot be taken to mean that living in a deprived neighborhood is bad for one's health, others like Feng \& Myles (2004), opined that more unequal communities will not generate the social cohesion that will make for healthy population, notwithstanding whether such communities are rich or poor. According to them individuals who live in high inequality neighborhood are likely to exhibit poorer health irrespective of their own income level and also, people who share neighborhood with more affluent families are likely to be less healthy.

While on one hand, Malmstrom et al (1999), believe that though, studies have shown that there is relationship between socioeconomic status, lifestyle and self reported health status, yet, the influence of neighborhood on these variables is still unclear. They explained that a multilevel analysis indicates that there are neighborhoods where high prevalence of illness was clustered but this is not fully accounted for by the individual characteristics of the living in the area.

Arleen et al (2007) quoting Kaplan et al. (1987), Kaplan \& Yen (1999), Winkleby \& Cubbin (2003), Patel et al (2003), Stafford \& Marmot (2003) explained that residence in a socio economically deprived neighborhood has been linked to allcause mortality, functional decline, poorer health status and 
higher incidence and prevalence of chronic conditions. They explained further that those who live in deprived neighborhood are likely to experience poorer health.

This unavailability of common position on the effect of neighborhood deprivation on health not withstanding, researchers believe that there is need for individuals to be able to rate how they perceive their own health within the context of their neighborhood.( Mansson and Merlo, 2001; Idler,1997 ; Malmstrom et al.,1999) ). Ailinger (1989), in his support for self-rating of health explained that they are good measures of health status because they are an economical means of gathering data on health and they are also useful in other areas such as predicting hospital admission and nursing home placement, particularly in older people. According to him, self assessment of health is influenced by culture as there is no culture that does not have answer to the question " Am I healthy?". However, while emphasizing the importance of self-rated health, Kind \& Dolan (1995), advised that methodological issues such as; how such values are to be described, the choice of method for generating data, how individual responses are aggregated and whose values should count are to be taken seriously.

Many researchers have justified the use of self rated health (SRH ) as a measure of quality of life and predictor of morbidity and mortality (Bosworth et al, 1999; Mansson \& Merlo, 2001); Friedsam \& Martin, 1963 in Maddox \& Douglass, 1973) . In their own finding, Cummins et al, 2005) explained that a health survey of Scotland and England shows that fair to very bad health was significantly associated with some neighborhood attributes such as poor physical residential environment, high unemployment and lower access to private transportation.

The present study intends to identify such neighborhood deprivation indices in Lagos State, Nigeria and examine their effect on the way individuals perceive and rate their own health. The paper is divided into four sections.

\section{Materials and Methods}

The methodology for achieving the aim of this study are outlined below

\subsection{The Study Area}

Lagos State lies approximately between longitude $2^{0} 42^{\prime} \mathrm{E}$ and $3^{0} 42^{\prime} \mathrm{E}$ and latitude $6^{0} 22^{\prime} \mathrm{N}$ and $6^{0} 52^{\prime} \mathrm{N}$. It is bounded in the South by the Guinea Coast of the $180 \mathrm{~km}$ Atlantic Coastline, in the West by the Republic of Benin and in the North and East by Ogun State (Odumosu et al, 1999).

It has a total area of $3,577 \mathrm{~km}^{2}$ about 22 percent of which is water. (Oke et al., 2001). Despite its position as the smallest State in the Federation in terms of land mass, occupying only $0.4 \%$ of the area of Nigeria, it has gone through series of administrative transformation to metamorphose into a frontline position amongst the thirty-six states making up the federation of modern day Nigeria.

Lagos State with a population of over 13 million is the most urbanized state in Nigeria. (WHO, 2004) over 50\% of industries in Nigeria are located in the State, contributing about $70 \%$ of the national gross industrial output. (Oke et al., 2001). The State accommodates about $6.2 \%$ of the total population of Nigeria and its annual population growth rate is over $9 \%$. 


\subsection{Description of Data}

Data were obtained from the questionnaires distributed to a random sample of 2000 respondents in the twenty local government areas in the state, out of which 1510 were completed and returned.. The instrument of data collection was partitioned into six sections with each section representing an index of deprivation in the neighborhood. There is a section for personal details such as sex, age, marital status, number of children, educational qualification, income, number of dependants who reside in the same household, Number of dependants who are not living within the same household and position in office. Information was sought on the type of residence; ownership of house; annual rent paid; number of rooms occupied; ownership of a car; distance of office or school of children from home; mode of transportation to and from home to destination; convenience of mode of transportation; accessibility of residence to other essential amenities like recreational facilities. Location of residence, type of road leading to residence, accessibility to water and electricity were recorded. Other information sought included whether the individual has suffered any ailment in the past one year; number of times the respondents has been to the hospital in the past one year; whether the respondent has lost neighbor(s) in the past one year; cause of death of the neighbor; use of generator in the area; the number of neighbors using generator; residential safety; membership of residential community and friendship with neighbors.

Following the index used by Arleen et al, (2007), SRH was used as the dependent variable. This was treated as a separate question intended to evaluate the respondent's perception of his own health condition. The respondents was asked the question "How will you rate your own current health

\section{8 | Dr. Rasheed Kola Ojikutu}

condition?". The responses were scored as 2, 1 or 0 as good, fair and poor respectively.

The indices of neighborhood deprivation described above were extended to include all the variables in the questionnaire.

\subsection{Data Analysis}

The hypotheses, $\mathrm{H}_{0 \mathrm{i}}$ : Is there significant relationship between variable $i$. ( $i=1,2,3,4 \ldots . . .30)$ and self rated health (SRH) were tested using $\chi^{2}$ to ascertain the veracity of the relationship between SRH and each of the variables. Chisquare was chosen because it is one of the most appropriate statistics for categorical data analysis. In addition to this, the study examined the interaction of all the indices of deprivation and their components with SRH for the purpose of establishing their contribution to the perception of the individual about his own health. To achieve this, a general hypothesis $\mathrm{H}_{0 \mathrm{~g}}$ : General neighborhood deprivation is not responsible for the way an individual rates his health was tested on a regression model, using SRH as the dependent variable and the other thirty or more variables as predictor variables

A regression model of the form $y_{j}=\beta_{0}+\sum_{j=1}^{37} \beta_{j} x_{j}$ is fitted to the data using the stepwise technique with $y_{j}(\mathrm{SRH})$ as the dependent variable, The intention here is to obtain a functional relationship between $y_{j}$ and $x_{j}$ where $x_{j}$ are the indices of neighborhood deprivation and the respondent's perception of his own health. All the variables were coded and analyzed using SPSS 10.

The difference between $\mathrm{i}$ and $\mathrm{j}$ in this case is that whereas, there are thirty variables, some of the variables have sub 
levels which are treated separately as individual variables in the regression analysis. There are additionally seven such variables, making a total of thirty-seven predictor variables used in the regression analysis.

\section{Results}

This study adopts two methods of analysis. First, the data collected are subjected to an initial descriptive analysis to get the salient features of the population of study and also tests simple hypotheses on the various population characteristics. Secondly, a regression model was fitted to obtain the functional relationship between SRH and all the predictor variables.

\subsection{Demographic Characteristics of the Neighbor- hood Data}

A total of 1520 individuals participated in the study. Of these, $22.1 \%$ were below 25 years, 34.7\% were between 26 - 30 years age while, $28.1 \%$ were in the $31-40$ years age old group and the remaining $15.2 \%$ were $\geq 41$ years old. It is to be noted that about $85.5 \%$ of the respondents were youth who are $\leq 40$ years old who, under normal situation should rate their own health as good. There were slightly more females (52.1\%), than male (47.9\%).

On the average, each respondent has about two relations who were dependent on him for livelihood, living within the same apartment and two others in the same dependence category living outside. This is to say that each respondent had on the average four other dependants apart from members of his nuclear family. Of all the respondents, $14.8 \%$ of those in our survey never attended school, while 14.2 percent had up to primary school education; $12.2 \%$ had up to secondary school education, $12.5 \%$ had polytechnic education and the remaining $46 \%$ had university education. As many as $42.6 \%$ of the respondents have no fixed income while the remaining $57.4 \%$ were workers in various income categories. It was observed that the percentage of those without fixed income ( a good number of them possibly unemployed) when combined with the number of low income earners amongst those with fixed income in our survey could reveal the economic deprivation within the population.

\section{Type of residence and Ownership of accommodation}

The study reveals that $53.8 \%$ of the respondents lived in tenement apartments, popularly referred to in local parlance as 'face- me, I face you'. $31.7 \%$ lived in flats, $6.3 \%$ in duplex and $8.3 \%$ in other types of apartments. It was found that $48.8 \%$ of the respondents lived in one room apartment with their family while $72.9 \%$ lived in accommodation containing three rooms or less.

A large number of respondents (72.9 per cent) lived in rented apartments while only $27.1 \%$ own their homes.

\section{Means of transportation, roads and access to portable water}

About a third,(37.6\%) of the respondents commuted to the office by bus, $24.8 \%$ by motorcycles locally called Okada, and the remaining by other means of transportation such as taxi, kabukabu (cab), company vehicles and use water transportation. Of the respondents, $81.2 \%$ did not own a car and therefore had to commute to and from their destinations by public transport, which are largely run by private organizations. Despite the indication of deprivation in the area of transportation, considering the large number of people who had to rely on the grossly inadequate and below standard public transportation system in the state, it was noted that $17.5 \%$ of the respondents found the mode of transportation very convenient, $46.2 \%$ just convenient while only $4.5 \%$ found it unbearable and $12.5 \%$ were undecided.

About half (52.2\%) of the respondents lived on streets with tarred roads, $44.9 \%$ lived on streets with motor able but 
untarred roads while the others lived on streets with impassable roads. Despite the position of Lagos as a mega city state, only $27.4 \%$ of the residents have access to pipe borne water while over $30.7 \%$ got water from bore-hole, water vendors, well and streams.

Ninety-seven per cent of the respondents did not have access to electricity for more than six hours on any given day. A third (33.3\%) rarely had access to electricity while $22.4 \%$ did not have access to electricity for more than one hour daily. At least $87.8 \%$ of the respondents had neighbors who used generator on daily basis.

\section{Health and access to health facilities}

Over half $(56.1 \%)$ of the respondents claimed to have suffered from one form of ailment or the other in the past one year. Two thirds (67.3\%) had been to the hospital at least once in the past one year and $43.8 \%$ had visited the hospital two or more times in the past one year. Only 1.7 per cent of the respondents had been to the hospital more than five times in the year. Only $28.2 \%$ of the respondents lived within close proximity of a general hospital but $46.9 \%$ responded that they lived within close proximity of a hospital. About half ( 51.6\%) of the respondents claimed to have lost at least one neighbor in the past one year. $43.7 \%$ had lost at least two neighbors while $4.6 \%$ had lost three or more neighbors, though, most of them did not know the cause of death.

Considering that more than 85 per cent of the respondents are 40 years and below, the above statistics may be an indication of poor state of health in the population.

\section{Neighborhood Security and participation}

Only $27.4 \%$ of the respondents considered the precinct of their residence to be free from crime. $31.7 \%$ reported that armed robbery is a common crime in their locality while
$33.7 \%$ see the 'area boys' (common local name for street urchins)menace as most prominent in their locality. On the other hand, $12.4 \%$ of the respondents were wary of the presence of drug peddlers and users within their neighborhood .In terms of time of insecurity, $26.7 \%$ of the respondents felt most insecure during the day, 30.5\% at night, $3.0 \%$ through out the day while $20.8 \%$ did not feel insecure at any time of the day.

Despite the almost all-pervading neighborhood insecurity reported by the respondents, $(72.6 \%$ of the people did not find their locality secure), over $64 \%$ of them did not feel that such security problem could lead to physical injury or death to their person. This self-assurance not withstanding, over $40 \%$ of the respondents had burglar proof or high fence erected to protect their homes. Slightly over $21 \%$ of the respondents felt protected by the presence of the Nigerian Police while the remaining $78.9 \%$ made provision for their own security through the use of the local militia group turned neighborhood watchers.

Only about $28.4 \%$ of the residents participated in neighborhood meetings while as many as $53.1 \%$ did not have friends in their locality. About $50.2 \%$ of the people did not have reasons or consider it necessary to visit the homes of neighbours.

\subsection{Self Rated Heath and Other Variables}

Within sex, $59.3 \%$ of the female and $56.3 \%$ of the male respondents rated their own health as good. $34.5 \%$ of the males and $38.6 \%$ of the females rated their own health as fair while only $6.2 \%$ of the male and $5.1 \%$ of the female rated their own health as poor and very poor. Self rated health was found to be similar between males and females $\left(\chi^{2}=3.219\right.$; $\mathrm{p}>0.01)$. 
Majority (72.9\%) of respondents $<25$ years old had a good rating of their health. $25 \%$ of them felt their health is fair while $2.1 \%$ rated their health as poor. In the 26 to 30 years category, $57.1 \%$ rated their own health as good, $35.2 \%$ rated it as fair while $7.6 \%$ rated it as poor.. In the over 51 years age category, $47.8 \%$ felt that their own health is good, $47.8 \%$ perceived it as fair while $4.3 \%$ rated it as poor. The good rating of health decreased with advancement in age $\left(\chi^{2}=59.096 ; \mathrm{p}<0.01\right)$.

Over half $(57.8 \%)$ of those who had dependants rated their own health as good, $36.6 \%$ felt it was fair while $5.6 \%$ thought their health was poor. There was a significant relationship between SRH and number of dependants that the respondent cater for $\left(\chi^{2}=130.152, \mathrm{p}<0.01\right)$.

Table 1: The frequency of self rated health of the individuals in Lagos State.

\begin{tabular}{|lccll|}
\hline Ranking & Frequency & Percent & Valid\% & Cumulative\% \\
\hline Excellent/Good/ & & & & \\
Very Good & 875 & 57.8 & 57.8 & 57.8 \\
Fair & 555 & 36.6 & 36.6 & 94.4 \\
Poor/very poor & 85 & 5.6 & 5.6 & 100.0 \\
Total & 1515 & 100.0 & 100.0 & \\
\hline
\end{tabular}

Source: survey

A good proportion (56.3\%) of those who had never been to school rated their own health as good, $37.5 \%$ of them perceived their health to be fair while $6.3 \%$ rated them as poor. Amongstthose with primary school education, $55.8 \%$ have feeling of good health, $41.9 \%$ rated their ownhealth as fair and $2.3 \%$ as poor. Amongst those who have been to the University or Polytechnic,63.2\% rated their own health as good, $31.6 \%$ as fair and $5.3 \%$ as poor. Amongst those whocompleted secondary school education, 59.5\% rated their health as good, $37.8 \%$ as fair and $2.7 \%$ as poor. It is noteworthy that the rating of health as excellent increases with level of education.He rating of health as excellent increased with level of education. ( $\chi^{2}=58.849$, $\mathrm{p}<0.01$ ).

Amongst the people with no fixed income, $42.3 \%$ rated their own health as good, $44.1 \%$ as fair and $4.7 \%$ as poor. The low income earners rating differs markedly from those without fixed income as $88.9 \%$ rated their own health as good, nobody rated his health as fair and $11.1 \%$ gave the rating as poor. In the middle income group, 56.3\% rated their health as good, $37.5 \%$ as fair and $6.3 \%$ as poor while all the higher income earners rated their own health as good. In general, with respect to income, $57.8 \%$ of the people rated their health as good, $36.6 \%$ as fair and $5.6 \%$ as poor. The test of independence also showed a significant relationship between Income and SRH $\left(\chi^{2}=414.477, \mathrm{p}<0.01\right)$.

Over half (58.6\%) of those in tenement apartments rated their health as good,35.9\% as fair while $5.5 \%$ as poor. Amongst those who live in flats, $60.4 \%$ perceived their own health as good, $32.3 \%$ as fair and $7.3 \%$ as poor. Those who live in duplex generally rated their health as either good (52.6\%) or fair (47.4\%) as nobody perceived his own health as poor. It is interesting that those who lived in self-contained apartments didn't see their own health as very good. Only $37.5 \%$ of them rated their own health as good, $56.3 \%$ as fair while $6.3 \%$ as poor. There was significant association between type of accommodation and SRH $\left(\left(\chi^{2}=39.23, \mathrm{p}<0.01\right)\right.$.

Those who lived in rented apartments seems to perceive their own health as not better than those who live in their own house. $59.7 \%$ of those who live in their own house rated their health as excellent as against $57.9 \%$ amongst those who live in rented accommodation), $43.3 \%$ of them perceived their 
own health as fair ( $33.5 \%$ for those in rented accommodation) and $3.3 \%$ rated their own health as poor (6.8\% for those in rented apartment). The type of accommodation was significantly related to SRH. $\left(\chi^{2}=26.610 ; \mathrm{p}<0.01\right)$.

There was significant relationship between number of rooms occupied by the respondent and his SRH $\left(\chi^{2}=84.709\right.$, p < $0.01)$. Good rating of health increased with increase in the number of rooms occupied by the respondents. Some, 58.1\% of one room occupants rated themselves as having good health. This was lower compared to $58.9 \%$ recorded by those who occupied two rooms and $61.2 \%$ for those occupying three or more rooms. In the same vein, $36.3 \%$ of one room occupants rated their own health as fair while $35.6 \%$ of two room occupants and $32.7 \%$ of those who occupied three or more rooms rated themselves as having fair health. Finally, $8.3 \%, 5.6 \%$ and $6.1 \%$ of those occupying one room, two rooms and three rooms or more respectively, rated their own health as poor.

Half $(50.0 \%)$ of those who owned cars rated their health as good, this was lower than $58.5 \%$ for those without cars. Moreover, $44.6 \%$ of those with cars perceive their health as fair while $35.5 \%$ of those without cars fall within the same category. Only a few of those with $(5.4 \%)$ or without $(6.0 \%)$ cars rated their health as poor. There was observed, a significant difference between ownership of a car and SRH $\left(\chi^{2}=21.029 ; \mathrm{p}<0.01\right)$.

All respondents who commuted to their offices by taxi perceived their health as good, whereas, $56.1 \%$ of those who used commercial mini buses (locally called “danfo”), 54.7\% of those who ride motorcycles and $45.7 \%$ of those who used other means of transportation rated their own health as good.
The mode of transportation was found to be significantly related to SRH with $\left(\chi^{2}=136.765, \mathrm{p}<0.01\right)$

More (67.3\%) of the respondents who lived on streets with untarred roads perceived their health as good than those (56.6\%) who lived on streets with tarred roads. Some (35.9\%) of those on tarred roads and $30.8 \%$ of those on untarred roads perceived their own health as fair and $7.6 \%$ and $1.9 \%$ respectively rated their own health as poor. Type of road leading to residence has significant relationship with SRH $\left(\chi^{2}=109.018, \mathrm{p}<0.01\right)$.

As regards to access to water, $54.2 \%$ of those who have access to public tap water and $40 \%$ of those who obtained it from other sources rated their health as good while $42.2 \%$ and $30 \%$ respectively rated their health as poor. It was observed that as much as $30 \%$ of those who obtain water from other sources other than government tap perceived their own health as poor compared to $3.6 \%$ of those who use tap water. There was a significant relationship between access to portable tap water and SRH $\left(\chi^{2}=125.743\right.$, $\left.\mathrm{p}<0.01\right)$.

The majority (94.2\%) of those who have been to the hospital in the last one-year and none of those who had visited the hospital more than three times perceived their health as good while $4.3 \%$ of those who have been to the hospital only once and $81.3 \%$ of those who had been more than three times rated their health as fair. Health was rated as poor by $18.8 \%$ of those who had visited the hospital more than three times and $1.4 \%$ of those who have done so once. The chi-square test showed that number of visits to the hospital was significantly related to SRH $\left(\chi^{2}=1728.462, \mathrm{p}<0.01\right)$.

\subsection{Model Summary}

Table1 and Table 2 show that the model in equation (1) is significant with a coefficient of determination $r^{2}=0.644$. 
This shows that $64.4 \%$ of the variation in self rated health is explained by variation in the neighborhood deprivation indices and other variables used as predictor variables in the equation.

Table 1: Model summary

\begin{tabular}{|c|c|c|c|c|c|c|c|c|c|}
\hline $\begin{array}{l}\bar{d} \\
\frac{0}{2} \\
\end{array}$ & $\mathrm{R}$ & $\begin{array}{c}\mathrm{R} \\
\text { Square }\end{array}$ & $\begin{array}{c}\text { Adjus } \\
\text { ted R } \\
\text { Squa } \\
\text { re }\end{array}$ & $\begin{array}{c}\text { Std. } \\
\text { Error } \\
\text { of the } \\
\text { Estima } \\
\text { te }\end{array}$ & \multicolumn{5}{|c|}{ Change Statistics } \\
\hline & & & & & $\begin{array}{c}\mathrm{R} \\
\text { Square } \\
\text { Chang } \\
\mathrm{e} \\
\end{array}$ & $\begin{array}{c}\text { F } \\
\text { Chang } \\
\mathrm{e}\end{array}$ & df1 & df2 & $\begin{array}{l}\text { Sig. } \\
\text { F } \\
\text { Chan } \\
\text { ge }\end{array}$ \\
\hline 1 & $.803(a)$ & .644 & .633 & .36 & .644 & 55.320 & 48 & 1466 & .000 \\
\hline
\end{tabular}

b Dependent Variable: self rated health of the individual

Table 2: ANOVA

\begin{tabular}{|l|l|r|l|l|l|}
\hline Model & Sum of squares & df & Mean Square & F & Sig \\
\hline 1 & & & & & \\
Regression & 353.106 & 48 & 7.356 & 55.320 & $000^{\mathrm{a}}$ \\
Residual & 194.947 & 1466 & .133 & & \\
Total & 548.053 & 1514 & & & \\
\hline
\end{tabular}

Dependent Variable: self rated health of the individual

\section{Discussion}

We found that serious neighborhood deprivation exists in Lagos State, Nigeria. Most of the residents in the state are highly deprived in terms of basic neighborhood amenities such as good portable water, good roads, fresh and unpolluted air, noise free environment, good waste disposal system, uninterrupted electricity supplies, crime free environment and so on. This high level of neighborhood deprivation may partly account for the high crime rate and feeling of insecurity experienced by the respondent. It is note worthy that majority of the people do not find their locality secure and make provision for their own security because of scanty provision for neighborhood security by the government.

In terms of health, most respondents claimed to have visited the hospital more than once in the past one year. While a huge percentage claimed to have visited the hospital for one form of ailment or the other in the past one year, about half of the people have done so more than two times in one year. More disturbing is the fact that half of the respondents claimed to have lost at least one neighbor in one year. These figures may suggest general increase in morbidity and mortality in the state, a situation that calls for further investigation and interventions.

In spite of the serious neighborhood inadequacies and the gloomy statistics presented by our survey, the self-rating of health by the respondents may not be in total agreement with Arleen et al (2007), which posit that inadequate neighborhood resources may result in functional impairment which in turn may influence the way an individual perceive his own health. Despite the high level of neighborhood limitations, over half, of the respondents still rated their own health as good. The regression model shows that most neighborhood indices and other predictor variables in this study may be responsible for the way individuals rated their own health. An indication that proper government intervention is required in many areas, particularly in the delivery of sound public health strategies, to ameliorate the less than acceptable standard of facilities and other infrastructures within the state.

\section{Reference}

Arleen.F. B, Ang.A. \& Pebley.A.R (2007). The Relationship Between Neighborhood Characteristics and Self - Rated Health for Adults With Chronic Conditions. American Journal of Public Health , 97 , 927-932 


\section{Dhaulagiri Journal of Sociology and Anthropology Vol.2 | 209}

Ailinger.L. R. (1989). Self- assessed health of Hispanic Elderly Persons Journal of Community Health Nursing, 6, 113-118

Bosworth H.B, Siegler I.C, Brummet B.H, Barefoor J.C, Williams R.B, Clap-Channing N.E \& Mark D.B (1999).The Association between Self-rated Health and Mortality in a Well-Characterized Sample of Coronary Artery Disease Patients. Medical Care 37(12),

Cummins.S., Stafford.M, Macintyre.S, Marmot.M and Ellaway.A (2003) Neighborhood Environment and its association with selfrated health: evidence from Scotland and England, J.Epidemiol. Community Health,59, 207-213

Feng H. \& Myles.J (2004). Neighborhood Inequality, Relative Deprivation and Self-Perceived Health Status Analytical

Studies-Research Papers Series, Statistics Canada 11F0019 No 228.

Idler.L.E (1997). Self Rated Health and Mortality: A review of Twenty-Seven Community Studies Journal of Health and Social Behaviour, 38, 21-37.

Paul K \& Paul D. (1995). The Effect of Past and Present Illness Experience on the valuations of Health States, Medical Care, 33,AS255-AS263

Maddox.G.L \& Douglass E.B (1973).Self-assessment of Health: A Longitudinal study of elderly subjects, Journal of Health and Social Behavior.14 : 87-93

Mansson Nils-Ove \& Merlo Juan (2001). The Relation between Self Rated Health, Socio-Economic Status, Body Mass Index and Disability Pension among Middle-Aged Men, European Journal of Epidemiology,17: 65-69

Malmstrom M., Sundquist J. \& Johansson Sven-Erik (1999). Neighborhood Environment and Self-Reported Health Status: A Multilevel Analysis American Journal of Public Health, 89, 11811186

\section{$210 \mid$ Dr. Rasheed Kola Ojikutu}

Odumosu T, Balogun Y.\& Ojo. K (1999). (ed) Lagos State in Maps, Rex Charles Publication, Ibadan pp1-50

Oke O, Julie Victor -Ahuchogu (2000). Report of the In-Depth Assessment In Selected Local Governments- Implementing Aids Prevention and Care Project ( IMPACT) USAID, Family Health International

Oke A, Adedokun L, Soretire F, \& Faweya O. (2001). Lagos State, Nigeria: Report of the In-Depth Assessment of the HIV/AIDS Situation- Implementing Aids Prevention and Care Project ( IMPACT) USAID, Family Health International

WHO (2004). Cardiovascular Disease, World Health Organization Geneva.

Available ...http://www.who.int/cardiovascular_disease/en/ 